\title{
Pulmonary necrobiotic nodules: a rare extraintestinal manifestation of Crohn's disease
}

\author{
G. Warwick*, T. Leecy\#, E. Silverstone ${ }^{\Uparrow}$, S. Rainer ${ }^{+}$, R. Feller ${ }^{\S}$ and D.H. Yates*
}

\begin{abstract}
The present article reports the case of a 22-yr-old female with new onset Crohn's colitis, anterior uveitis and multiple pulmonary nodules which, on histological examination, were necrobiotic nodules. This is a rare but recognised pulmonary extraintestinal manifestation of Crohn's disease and only the fourth reported case. The present case report is followed by a brief review of the relevant literature.
\end{abstract}

KEYWORDS: Crohn's disease, high-resolution computed tomography, interstitial lung disease, necrobiotic nodules

$\Delta$ 22-yr-old scientist, of Ashkenazi Jewish origin, with no relevant past medical history was referred for respiratory review after noticing pleuritic chest pain and mild breathlessness. Her chest pains were fleeting and bilateral and she had also noticed a sensation of inability to take a deep breath. A chest radiograph, requested by her GP, was abnormal. She had a history of mild but persistent nonbloody diarrhoea, nausea and $4 \mathrm{~kg}$ weight loss, with some slight blurring of vision over a period of 2 months. She had subsequently developed headache of acute onset with mild photosensitivity and presented to an eye hospital where she was diagnosed with anterior uveitis. This had responded to topical prednisone and cyclopentolate. On questioning, she also admitted to noticing mild weakness and stiffness of the hands and some ankle pain. On further questioning she described no fevers or sweats.

On examination the patient was noted to have a small, pustular eruption on her cheek and neck but no other rashes. There was no lymphadenopathy and respiratory, cardiac and abdominal examinations were unremarkable. A chest radiograph showed a prominent right paratracheal stripe and multiple, bilateral rounded opacities in the mid zones, $\sim 1.5 \mathrm{~cm}$ in diameter. A computed tomography (CT) scan of the chest revealed multiple irregular nodules, some of which were pleurally based (figs 1 and 2). There was left paraaortic lymphadenopathy at the level of the kidneys. Pulmonary function testing showed normal spirometry with no bronchodilator reversibility, normal lung volumes but a mild reduction of the diffusing capacity of the lung for carbon monoxide per unit of alveolar volume as assessed by the single breath method (61\% predicted).

Laboratory investigations showed a normal full blood count but slightly low serum iron $\left(8 \mu \mathrm{mol} \cdot \mathrm{L}^{-1}\right)$, normal electrolytes including calcium and normal liver function tests and serum angiotensin-converting enzyme level. Autoantibodies, immunoglobulins, complement and serum electrophoresis were all within normal limits, as was coeliac serology. The patients' C-reactive protein was 1.0 while her erythrocyte sedimentation rate was $30 \mathrm{~mm} \cdot \mathrm{h}^{-1}$. Upper gastrointestinal endoscopy was normal but colonoscopy revealed multiple small, well-circumscribed ulcers scattered throughout the colon with relative rectal sparing. Histology showed superficial ulceration associated with an acute and chronic inflammatory cell infiltration and focal granuloma formation. There was focal and only very subtle mucosal architectural distortion. Stains for fungi and acid fast bacilli were negative. Biopsy of the skin lesion on the patients' neck revealed a dermal lymphoid proliferation with predominant B-cells consistent with a reactive lymphoid hyperplasia or pseudolymphoma. CT-guided biopsy of a lung nodule revealed a granulomatous appearance with numerous epithelioid histiocytes arranged in indistinct nodules with an infiltrate of lymphocytes, plasma cells and multinucleated giant cells (figs 3 and 4). In
AFFILIATIONS

*Depts of Thoracic Medicine

"Radiology,

+Histopathology,

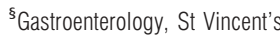

Hospital, and

\#Dept of Histopathology, Royal North

Shore Hospital, Sydney, Australia.

CORRESPONDENCE

D.H. Yates

Dept of Thoracic Medicine

St Vincent's Hospital

390 Victoria Street

Darlinghurst

NSW 2010

Australia

Fax: 61283822359

E-mail: deborahy88@hotmail.com

Received:

October 082008

Accepted after revision:

December 012008

STATEMENT OF INTEREST

D.H. Yates was a co-investigator on a competitive peer-reviewed grant for

research funding which was

sponsored by a pharmaceutical

company (Actelion Young

Investigator Award).

PROVENANCE

Submitted article, peer reviewed.

European Respiratory Review Print ISSN 0905-9180

Online ISSN 1600-0617 


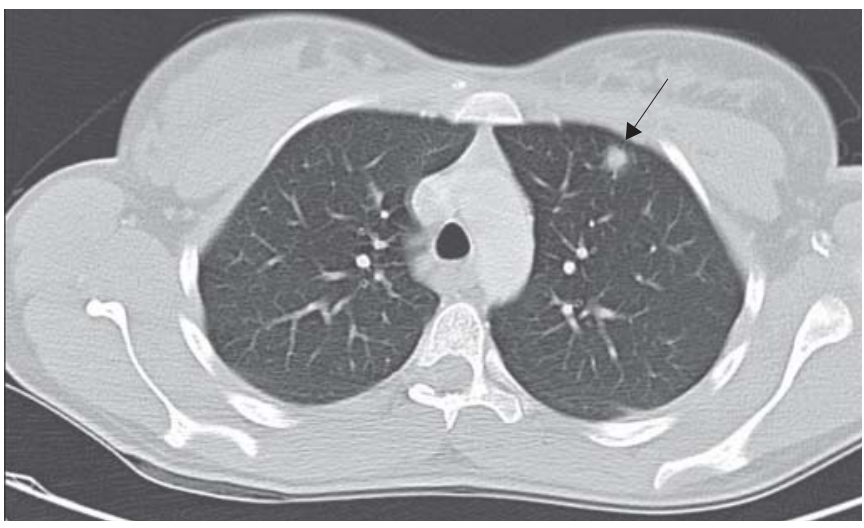

FIGURE 1. Axial computed tomography image showing soft tissue density in the left upper lobe (arrow) with a small amount of adjacent ground-glass shadowing

the centre of the biopsy core was a zone of necrobiosis. Once again, stains for mycobacteria and fungi were negative.

The lung nodules had begun to show radiographic improvement before any treatment was started, but the patient was still symptomatic with chest pain, mild dyspnoea and diarrhoea. She commenced treatment of $30 \mathrm{mg}$ oral prednisone and mesalazine, which was subsequently changed to balsalazide because of abdominal discomfort. Symptoms were well controlled on this regime. A subsequent chest $\mathrm{CT}$ scan showed a $>50 \%$ reduction in nodule size and no new lesions. Most recent chest radiographs show no visible lesions. The patient is currently well with no respiratory or gastrointestinal symptoms.

\section{DISCUSSION}

Crohn's disease is an inflammatory condition of unknown aetiology characterised by transmural, noncaseating granulomatous

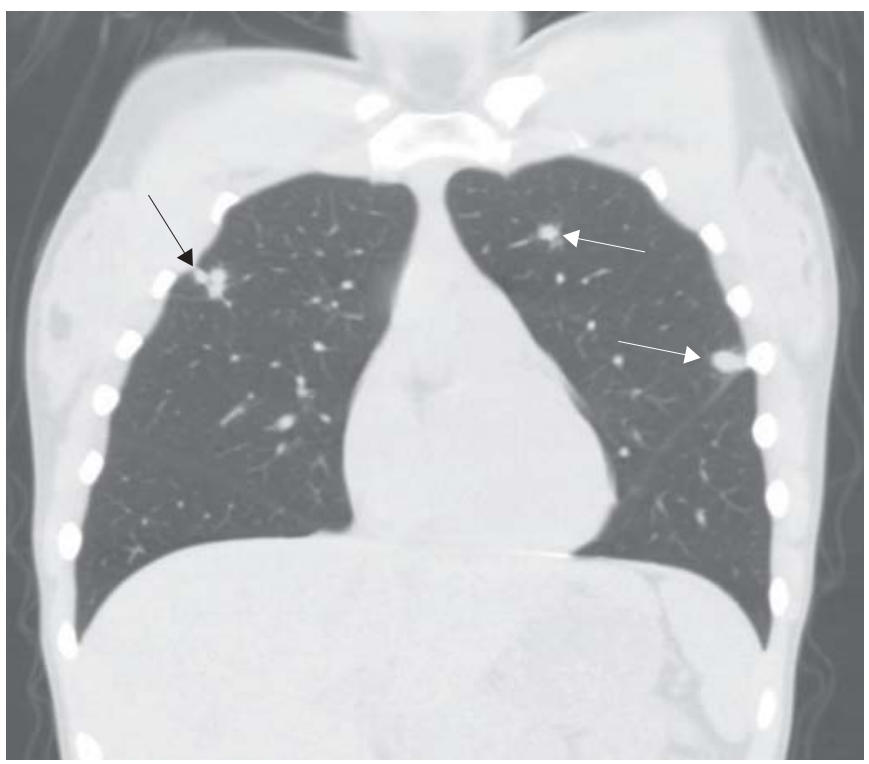

FIGURE 2. Coronal computed tomography image showing three nodules: one in the right upper lobe (black arrow) which is lobulated, and two in the left upper lobe (white arrows).

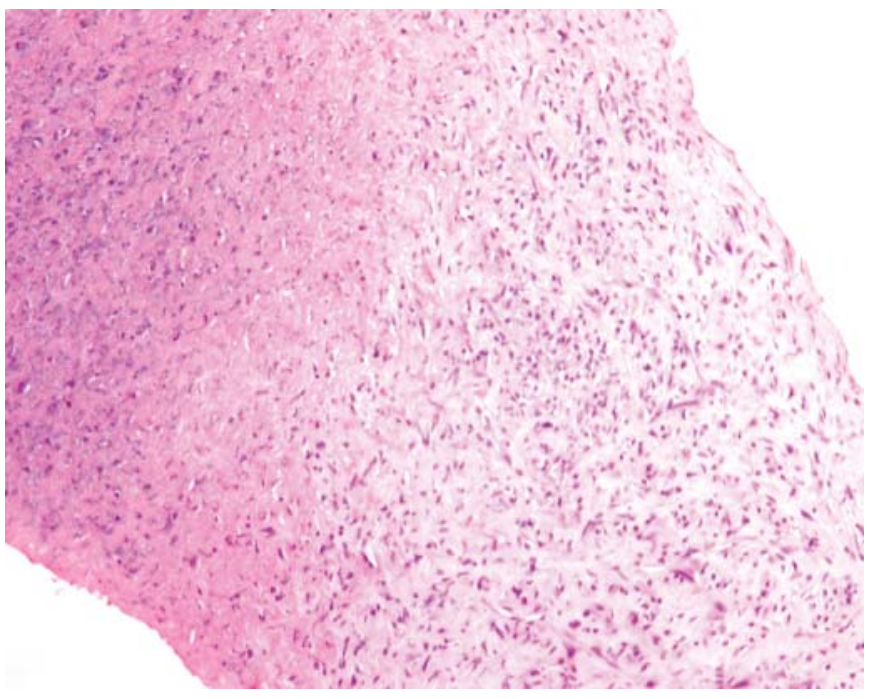

FIGURE 3. Haematoxylin and eosin staining of a lung needle biopsy showing a central region of necrobiosis surrounded by a zone of granulomatous inflammation.

inflammation of the gastrointestinal tract. Extraintestinal manifestations may occur in up to $25 \%$ of patients [1], including pyoderma gangrenosum, erythema nodosum, anterior uveitis, arthropathy, sacroiliitis, ankylosing spondylitis and primary sclerosing cholangitis, and genotypes with increased susceptibility have been demonstrated [2]. While more commonly seen in ulcerative colitis, there is increasing recognition of pulmonary manifestations of Crohn's disease.

The first report of lung involvement in Crohn's disease was published in 1976, when KRAFT et al. [3] reported six patients with nonspecific inflammatory bowel disease with chronic bronchitis with or without bronchiectasis. One of these cases had Crohn's disease. Since that report there have been small

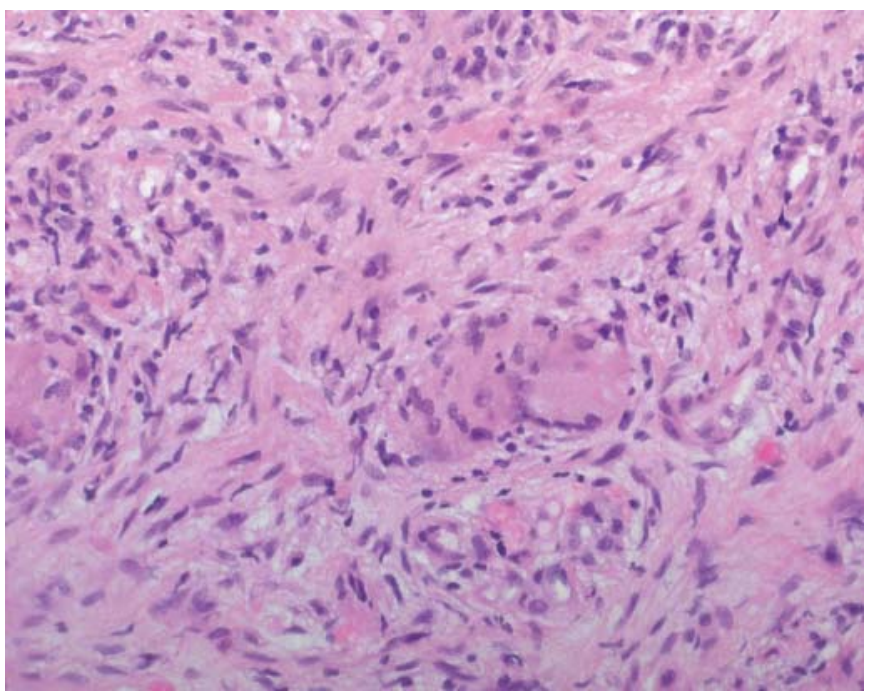

FIGURE 4. Haematoxylin and eosin staining of the zone of granulomatous inflammation showing numerous epithelioid histiocytes and scattered multinucleated giant cells. 
series but mostly isolated case reports. A spectrum of pulmonary involvement has been described, including: 1) airway disease (tracheal [4] and tracheobronchial [5] stenosis, tracheobronchitis [6], bronchitis [3], bronchiectasis [7], bronchiolitis [8] and asthma [9]); 2) interstitial lung disease (granulomatous alveolitis [10], bronchiolitis obliterans with organising pneumonia [11], interstitial fibrosis [12] and lung infiltrates with peripheral eosinophilia [13]); and 3) serositis (pleural thickening [12] and pleuropericarditis [13]).

The prevalence of pulmonary involvement in Crohn's disease is unknown but indirect evidence suggests it is common, at least subclinically. Lung function abnormalities are significantly more common in patients with inflammatory bowel disease (IBD) than controls [14] with reduced transfer factor being demonstrated in Crohn's disease in a number of studies [14-17]. Patients with IBD have bronchial hyperresponsiveness to methacholine [18] and impaired small airway function [17]. High-resolution CT scanning of IBD patients with respiratory symptoms may demonstrate bronchiectasis, bronchiolectasis and cellular bronchiolitis, even in the absence of lung function abnormalities [19].

Pulmonary involvement in Crohn's disease responds readily to glucocorticosteroids [20]. Interstitial lung disease can be treated with oral therapy, while airway disease may be treated with inhaled or nebulised budesonide. More aggressive airway inflammation may require oral steroids, while infliximab has been used successfully [21].

Although more commonly seen in ulcerative colitis, necrobiotic nodules are a rare pulmonary manifestation of Crohn's disease. Including the case presented herein, only four cases have been described and are summarised in table 1 . The first reported patient was a 38-yr-old female with a 3-yr history of Crohn's disease, with recurrent bronchitis and mucopurulent sputum, migratory lung infiltrates with peripheral eosinophilia and bilateral pleural thickening, who was treated with mesalazine [12]. Histopathological examination revealed necrotising nodules, eosinophilic infiltration of the nonabscessed tissue and areas of noncaseating epithelioid granulomas. The patient achieved complete radiological resolution on a tapered course of oral prednisolone, except for persistent bibasal pleural thickening.

The second patient was a 57-yr-old male with Crohn's disease with cough, fevers, dyspnoea and numerous cavitary lesions on chest radiography, which was well-controlled with mesalazine [22]. The lesions were confirmed to be necrobiotic nodules on histological examination. Symptoms and radiological appearance resolved completely with no additional therapy.

The third patient was a 37-yr-old male with a 7-yr history of Crohn's disease, treated with prednisone and metronidazole, who developed cough, fever and further weight loss. His CT scan showed innumerable small nodular opacities, which were up to $1 \mathrm{~cm}$ in diameter with small areas of cavitation [23]. A biopsy showed granulomatous bronchiolitis and necrobiotic nodules. Respiratory symptoms and CT changes resolved with prednisone.

In contrast, the current study patient's nodules were presumably the cause of her presentation, before any treatment

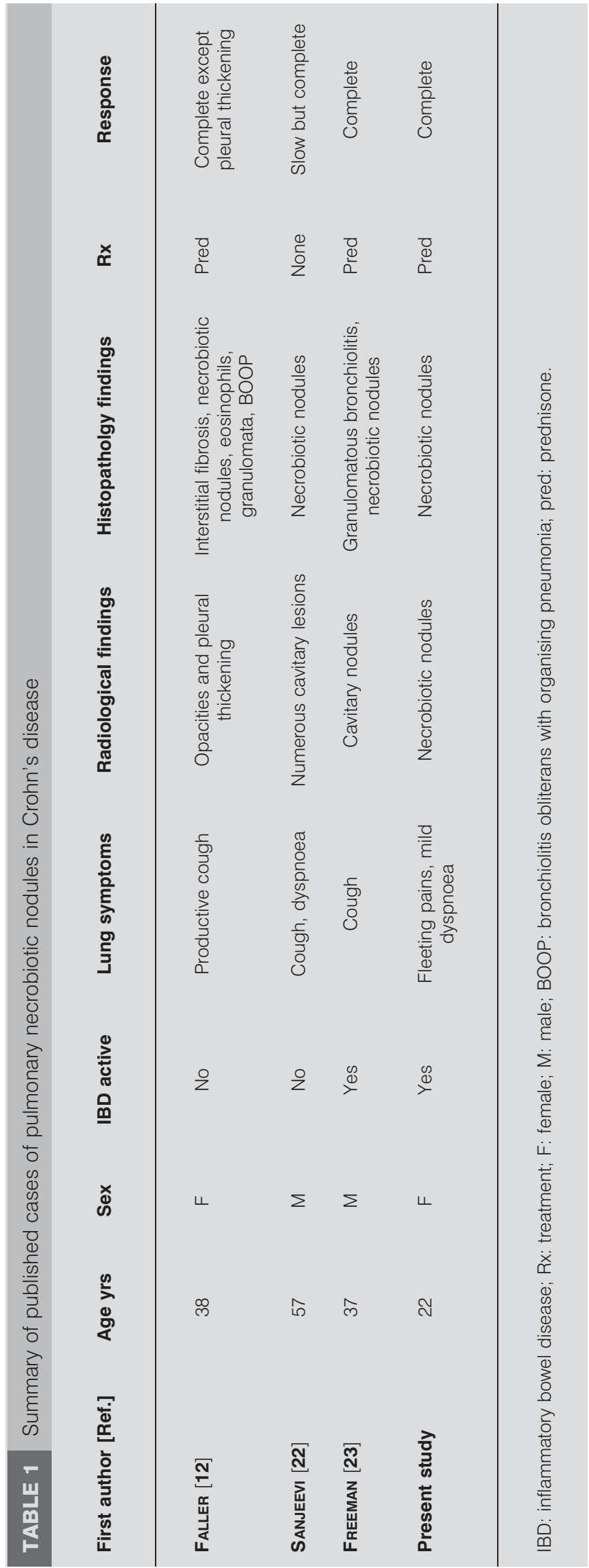


was started. Apart from fleeting, sharp, bilateral chest pains the patient only complained of mild breathlessness. In ulcerative colitis, necrobiotic nodules usually cavitate [13] and in two of the reported instances in Crohn's patients they have done so, but this was not true for the present study patient. Intestinal disease was inactive in two cases, while in the present case and one other, development of pulmonary disease coincided with gastrointestinal symptoms.

As in two of the three other reported cases, radiological resolution in the presented case was achieved by oral steroid therapy, although there had been some radiographic resolution prior to commencement of treatment.

In summary, the current authors present the fourth reported case of multiple necrobiotic pulmonary nodules in a young female with newly diagnosed Crohn's disease who responded to treatment with systemic steroids and 5-aminosalicylic acid therapy. While rare, pulmonary extraintestinal manifestations of Crohn's disease are well-recognised and respond well to steroid therapy. Lack of treatment may lead to long-term respiratory complications. Pulmonary Crohn's disease should be included in the differential of lung nodules and the relevant clinical history elucidated.

\section{REFERENCES}

1 Rankin GB, Watts HD, Melnyk CS, Kelley ML Jr. National Cooperative Crohn's Disease Study: extraintestinal manifestations and perianal complications. Gastroenterology 1979; 77: 914-920.

2 Rothfuss KS, Stange EF, Herrlinger KR. Extraintestinal manifestations and complications in inflammatory bowel diseases. World J Gastroenterol 2006; 12: 4819-4831.

3 Kraft SC, Earle RH, Roesler M, Esterly JR. Unexplained bronchopulmonary disease with inflammatory bowel disease. Arch Intern Med 1976; 136: 454-459.

4 Kinebuchi S, Oohashi K, Takada T, et al. Tracheo-bronchitis associated with Crohn's disease improved on inhaled corticotherapy. Intern Med 2004; 43: 829-834.

5 Bhat M, Dawson D. Wheezes, blisters, bumps and runs: multisystem manifestations of a Crohn's disease flare-up. CMAJ 2007; 177: 715-718.

6 Lamblin C, Copin MC, Billaut C, et al. Acute respiratory failure due to tracheobronchial involvement in Crohn's disease. Eur Respir J 1996; 9: 2176-2178.

7 Plataki M, Tzortzaki E, Lambiri I, Giannikaki E, Ernst A, Siafakas NM. Severe airway stenosis associated with Crohn's disease: case report. BMC Pulm Med 2006; 6: 7.

8 Vandenplas O, Casel S, Delos M, Trigaux JP, Melange M, Marchand E. Granulomatous bronchiolitis associated with
Crohn's disease. Am J Respir Crit Care Med 1998; 158: 1676-1679.

9 Bernstein CN, Wajda A, Blanchard JF. The clustering of other chronic inflammatory diseases in inflammatory bowel disease: a population-based study. Gastroenterology 2005; 129: 827-836.

10 Puntis JW, Tarlow MJ, Raafat F, Booth IW. Crohn's disease of the lung. Arch Dis Child 1990; 65: 1270-1271.

11 Alrashid AI, Brown RD, Mihalov ML, Sekosan M, Pastika BJ, Venu RP. Crohn's disease involving the lung: resolution with infliximab. Dig Dis Sci 2001; 46: 1736-1739.

12 Faller M, Gasser B, Massard G, Pauli G, Quoix E. Pulmonary migratory infiltrates and pachypleuritis in a patient with Crohn's disease. Respiration 2000; 67: 459-463.

13 Camus P, Piard F, Ashcroft T, Gal AA, Colby TV. The lung in inflammatory bowel disease. Medicine (Baltimore) 1993; 72: 151-183.

14 Kuzela L, Vavrecka A, Prikazska M, et al. Pulmonary complications in patients with inflammatory bowel disease. Hepatogastroenterology 1999; 46: 1714-1719.

15 Munck A, Murciano D, Pariente R, Cezard JP, Navarro J. Latent pulmonary function abnormalities in children with Crohn's disease. Eur Respir J 1995; 8: 377-380.

16 Tzanakis N, Bouros D, Samiou M, et al. Lung function in patients with inflammatory bowel disease. Respir Med 1998; 92: 516-522.

17 Tzanakis N, Samiou M, Bouros D, Mouzas J, Kouroumalis E, Siafakas NM. Small airways function in patients with inflammatory bowel disease. Am J Respir Crit Care Med 1998; 157: 382-386.

18 Louis E, Louis R, Drion V, et al. Increased frequency of bronchial hyperresponsiveness in patients with inflammatory bowel disease. Allergy 1995; 50: 729-733.

19 Mahadeva R, Walsh G, Flower CD, Shneerson JM. Clinical and radiological characteristics of lung disease in inflammatory bowel disease. Eur Respir J 2000; 15: 41-48.

20 Camus P, Colby TV. The lung in inflammatory bowel disease. Eur Respir J 2000; 15: 5-10.

21 Krishnan S, Banquet A, Newman L, Katta U, Patil A, Dozor AJ. Lung lesions in children with Crohn's disease presenting as nonresolving pneumonias and response to infliximab therapy. Pediatrics 2006; 117: 1440-1443.

22 Sanjeevi A, Roy HK. Necrobiotic nodules: a rare pulmonary manifestion of Crohn's disease. Am J Gastroenterol 2003; 98: 941-943.

23 Freeman HJ, Davis JE, Prest ME, Lawson EJ. Granulomatous bronchiolitis with necrobiotic pulmonary nodules in Crohn's disease. Can J Gastroenterol 2004; 18: 687-690. 